\title{
Roman et politique. Approche sérielle et intertextuelle du roman des Lumières
}

\section{Raymonde Monnier}

\section{Q OpenEdition \\ 1 Journals}

Édition électronique

URL : https://journals.openedition.org/ahrf/7953

DOI : 10.4000/ahrf.7953

ISSN : 1952-403X

Éditeur :

Armand Colin, Société des études robespierristes

Édition imprimée

Date de publication : 1 décembre 2006

Pagination : 175-177

ISSN : 0003-4436

Référence électronique

Raymonde Monnier, "Roman et politique. Approche sérielle et intertextuelle du roman des Lumières ». Annales historiques de la Révolution française [En ligne], 346 | Octobre/Décembre 2006, mis en ligne le 10 juillet 2008, consulté le 23 avril 2022. URL : http://journals.openedition.org/ahrf/7953 ; DOI :

https://doi.org/10.4000/ahrf.7953

Ce document a été généré automatiquement le 23 avril 2022.

Tous droits réservés 


\title{
Roman et politique. Approche sérielle et intertextuelle du roman des Lumières
}

\author{
Raymonde Monnier
}

\section{RÉFÉRENCE}

Youmna Charara, Roman et politique. Approche sérielle et intertextuelle du roman des

Lumières, Paris, Honoré Champion, 2004, 506 p., ISBN 2-7453-1048-8, $85 €$.

1 Croisant intertextualité et analyse sérielle, l'auteure se propose d'interroger les formes et le contenu d'une quarantaine de romans du XVIII ${ }^{e}$ siècle dans leur lien à l'expérience politique et institutionnelle. Il s'agit de dégager les lignes de force de l'évolution d'un certain nombre de modèles littéraires et l'expression des sensibilités politiques ou antipolitiques qui participent aux modifications stylistiques et narratives, dans le contexte particulier du siècle de la critique. S'agissant du roman, l'époque des Lumières peut apparaitre comme un véritable laboratoire dans la mesure où la désacralisation de l'autorité monarchique s'accompagne d'un travail de reconstruction d'un système de valeurs et de légitimité qui affecte les individus et la société dans leur rapport au pouvoir. Qu'il y ait solidarité entre l'histoire des formes littéraires et l'histoire culturelle, qui peut en douter? Mais dans quelle mesure et de quelle façon le mouvement des idées a-t-il modifié l'écriture romanesque et contribué à un renouvellement des genres, notamment après 1760 ? C'est en étudiant conjointement la représentation du lien politique et l'invention d'une écriture que l'auteure interroge trois grandes séries de récits, les romans à thèse qui visent à transmettre un sens, les romans historiques et les romans de la vie privée, centrés sur les relations familiales, sur le mariage ou les relations libertines.

2 Le roman du XVIII ${ }^{e}$ siècle se prête à l'approche sérielle, soit qu'il reprenne des situations ou des personnages-types, soit qu'il s'apparente à un modèle antérieur 
prestigieux, comme les Aventures de Télémaque ou l'Histoire des Sévarambes de Veiras, à des textes paradigmes comme les Lettres persanes ou La Nouvelle Héloïse, pour ne citer que ceux-là. La cohésion d'une série est d'autant plus significative que le roman noue des liens plus étroits avec des textes de philosophie politique, ce qui amène à privilégier certains scénarios et à se référer à un fond culturel commun. Ces effets de répétition tendent à unifier la production romanesque et à élargir la reconnaissance d'un genre, jusque-là jugé inférieur à la poésie et au théâtre, par une meilleure interprétation des œuvres. Dans le roman à thèse, la crise des idées politiques entraîne, d'un récit à l'autre, un glissement qui mène à une remise en cause des conventions littéraires et à un dérèglement des structures narratives. Même s'il subsiste des exceptions à la fin du siècle, c'est le cas de genres liés à l'origine au contexte de la monarchie absolue, comme le roman colonial, l'utopie ou le roman d'éducation du prince. Ce dernier finit par engendrer un anti-roman d'éducation; dans le roman utopique, la distanciation ironique (Cleveland) ou la fuite dans l'uchronie prophétique (L'An 2440) tendent à ruiner le modèle, tandis que le récit de fondation coloniale (ou de conquête coloniale) subvertit les situations et les rôles, notamment après l'Histoire des deux Indes de Raynal, sur le thème de la corruption de l'ordre colonial et de la révolte des tribus asservies (Les Incas de Marmontel) ou de l'esclave noir héroïque (du textesource d'Oronoko au Burg-Jargal de Hugo). L'inversion du système des personnages engendre un retournement des valeurs en faveur de l'examen du pouvoir absolu et de la résistance à la tyrannie. Télèphe, le roman de Pechméja réédité trois fois de 1784 à 1795, qui clôt la série critique dérivée du Télémaque, est une contre-initiation au métier de roi qui conduit à la condamnation de la royauté : Télèphe ne peut régner parce qu'il n'y a pas de bon roi. Dans la relation entre morale et politique, le transfert de légitimité morale entraîne des inversions radicales et une translation des attributs sacrés. Épisodes récurrents, ceux de la guerre civile et de la bataille montrent la force d'illustration du roman, qui entretient avec les ouvrages politiques et philosophiques, avec les théories du droit naturel et la rhétorique républicaine, des liens intertextuels d'autant plus étroits que beaucoup d'auteurs ont une double pratique d'écriture ou sont liés à l'aventure de l'Encyclopédie.

3 Le roman historique des Lumières, analysé dans la deuxième partie, ne se caractérise pas par l'invention d'une nouvelle écriture capable d'effacer le succès du genre au XVII siècle. Il est plus diversifié dans ses choix référentiels, d'époque ou de système des personnages (essentiellement l'entourage du roi et la noblesse), mais le récit de guerre est commun à tous, qu'il s'agisse de traiter du mythe du chef de guerre ou du spectre de la guerre civile. L'auteure retient les récits qui, des conflits du V $\mathrm{V}^{\mathrm{e}}$ siècle au Moyen Âge et aux révoltes $\mathrm{du} \mathrm{XVI}^{\mathrm{e}}$ siècle, orientent vers les controverses historiographiques contemporaines entre germanistes et romanistes, sur la liberté franque des origines, la montée de l'absolutisme, la résistance nobiliaire ou la tolérance religieuse. Dans la mesure où il tend à se détacher de l'anachronisme, le roman historique du XVIII siècle inscrit les relations sociales dans une situation et des événements connus des lecteurs, et participe de translations décalées ou polémiques qui ont acquis droit de cité dans le contexte politique des années 1770-1780. Genre en plein essor, analysé dans l'ouvrage du point de vue de l'évolution du rapport à l'autorité politique, le roman biographique présente, à côté de l'effacement du modèle héroïque par l'ironie dans le roman libertin, l'engagement militaire sur le thème individualiste de l'adhésion raisonnée: dans la relation triangulaire entre l'individu, le pouvoir et sa hiérarchie, la recherche de l'intérêt personnel tend à distendre le lien avec l'autorité et l'institution militaire ; la 
rupture est consommée dans le conte philosophique (Candide) où la logique de la préservation de soi délie du devoir d'obéissance.

4 La métaphore de la guerre revient dans la troisième partie qui traite de la politique des sexes, avec le roman du mariage et du libertinage. Ces derniers chapitres donnent une visibilité particulière à l'apport de l'analyse sérielle dans les relations privées, où le conflit entre la société et l'individu s'apparente à une configuration politique. Quand la corruption est générale, l'aliénation pénètre les sphères de la vie intime et des relations individuelles; aucune position ne met à l'abri de l'état de guerre. Le grand mérite de l'ouvrage est de donner, à côté de développements sur des fictions saturées de lectures critiques (les Lettres persanes, la Nouvelle Héloïse, les Liaisons dangereuses, etc.), des analyses convaincantes sur des textes beaucoup moins connus, comme l'unique roman de Jean-Louis Carra, Odazir ou le jeune Syrien, roman philosophique, composé d'après les mémoires d'un Turc (1772), en parallèle avec son essai philosophique publié l'année suivante, Le Système de la raison. On peut regretter que l'auteure ignore la belle biographie de Stefan Lemny sur le journaliste (L'Harmattan, 2000), ce qui lui aurait permis de mieux situer ces œuvres dans le parcours du révolutionnaire dans l'Europe d'Ancien Régime. La bibliographie de l'ouvrage de Youmna Charara est, il est vrai, moins pointue s'agissant de la philosophie politique et de l'histoire qu'en matière de critique littéraire. Mais l'analyse sérielle, en rapprochant le récit du voyage initiatique du jeune oriental du roman philosophique de Montesquieu, souligne les différences esthétiques et politiques et la radicalité républicaine du style de Carra. Dans Odazir, les personnages parlent le langage de la sensibilité et de la nature; la vibration affective est incompatible avec la satire, la rhétorique de la liberté est aussi celle de la résistance à la tyrannie. Entre la retraite du sage et la révolte, l'héroïne assume la vertu active de résistance, la liberté d'aimer au mépris de la mort: le récit de la révolte couronne une pensée et une écriture.

5 L'auteure note la co-existence durable de plusieurs tendances politiques dans le roman au XVIII siècle, où se fait jour une inspiration plus critique dans des fictions de plus en plus dramatiques au fil du siècle. L'approche sérielle et l'attention portée aux relations intertextuelles dans le contexte intellectuel de l'époque permettent de comprendre l'évolution des représentations et des structures narratives ainsi que les ruptures significatives introduites par certains romans. Il en est ainsi dans la série du libertinage du récit de Laclos, dont le dénouement tragique dévoile la logique politique de la domination et le vrai visage de la conquête : «La nature ne crée que des êtres libres; la société ne fait que des tyrans et des esclaves ", écrit-il ailleurs. Si le rapport réciproque entre fictions et textes d'idées est certain, il est plus difficile d'évaluer leur influence respective dans le public. En dépit de l'abondance et de la vigueur critique des textes philosophiques majeurs du siècle, le succès immédiat et le retentissement de certains romans incitent à la prudence. Merci à l'auteure de nous avoir engagés à lire et à relire autrement la production romanesque des Lumières. Retenons l'invitation au voyage qui permet de comprendre l'esprit d'une époque ; pourquoi ne pas aborder aussi la crise de la société d'Ancien Régime à la lumière des Liaisons dangereuses ou la philosophie politique de Constant par la lecture d'Adolphe? 